\title{
Correction to: The Immunoscore is a Superior Prognostic Tool in Stages II and III Colorectal Cancer and is Significantly Correlated with Programmed Death-Ligand 1 (PD-L1) Expression on Tumor-Infiltrating Mononuclear Cells
}

Takato Yomoda, $\mathrm{MD}^{1}{ }^{1}$, Tomoya Sudo, MD, PhD $^{1}$, Akihiko Kawahara, CT, PhD $^{2}$, Takahiro Shigaki, MD ${ }^{1}$, Susumu Shimomura, MD ${ }^{1}$, Kensuke Tajiri, MD $^{1}$, Sachiko Nagasu, MD, PhD $^{1}$, Fumihiko Fujita, MD, PhD ${ }^{1}$, Tetsushi Kinugasa, $\mathrm{MD}, \mathbf{P h D}^{1}$, and Yoshito Akagi, $\mathbf{M D}, \mathbf{P h D}^{1}$

${ }^{1}$ Department of Surgery, Kurume University School of Medicine, Kurume, Fukuoka, Japan; ${ }^{2}$ Department of Pathology, Kurume University School of Medicine, Fukuoka, Japan

CORRECTION TO: ANN SURG ONCOL (2019) 26:415-424

HTTPS://DOI.ORG/10.1245/S10434-018-07110-Z

In the original article, Akihiko Kawahara's first name is incorrect. It is correct as reflected here.

The original article can be found online at https://doi.org/10.1245/ s10434-018-07110-z.

(C) Society of Surgical Oncology 2019

Published Online: 29 January 2019

T. Yomoda, MD

e-mail: yomoda_takatou@med.kurume-u.ac.jp 